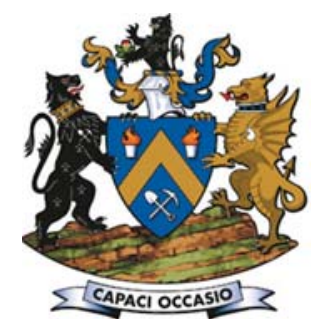

\title{
The Mutoshi Project - Part I: Metallurgical test work, process design, and project delivery
}

\author{
by P. Ilunga* ${ }^{*}$ D. Samal ${ }^{\dagger}$, M. Nicolle ${ }^{\ddagger}$, M. Lampi ${ }^{\S}$, \\ K. Valkama ${ }^{\S}$, J. Edwards ${ }^{\#}$, and N. Tatalias ${ }^{\#}$
}

\section{Synopsis}

Developing a greenfield mining project is a complex exercise: doing so in an increasingly volatile, uncertain, and ambiguous global economy adds significantly to this complexity. In the context of an elevated cobalt price, this paper outlines the metallurgical and process development of the Mutoshi copper-cobalt project for copper cathode and cobalt hydroxide production in the Democratic Republic of Congo. Chemaf has a long production history on the Copperbelt, a region widely perceived to be tough to operate in. This history stretches back to 2001, during which time the company has developed two copper-cobalt processing facilities. The experience gained in the development and operation of these two facilities has been used extensively in the Mutoshi copper-cobalt project. The metallurgical test work, process design, and project delivery approach are presented. Additionally, the decisions taken to minimize risk and maximize upside to the project are discussed.

Keywords

copper-cobalt, greenfield project, test work, process design, project delivery.

\section{Introduction}

Chemaf (Chemicals of Africa), a mining company located in Katanga province of the Democratic Republic of Congo (DRC), has been operating since 2001 with two major coppercobalt processing facilities: the Usoke and Etoile plants. In 2016, Chemaf acquired the Mutoshi mine, which belonged to Gécamines and had been explored by Anvil Mining since 2004 under a joint venture with Gécamines. Chemaf appointed African Mining Consultants Ltd (AMC) to undertake a preliminary economical assessment, then develop a JORCcompliant Mineral Resource estimate and finally a full life-of mine feasibility study. Both a Mineral Reserve and Mineral Resource were developed and the final life-of-mine feasibility study is to be published shortly. A metallurgical test work programme was initiated and carried out by Chemaf's research and development laboratory with assistance from the Chemaf process team. After completion of the initial test work, Chemaf developed a process design criteria document for a $20 \mathrm{kt} / \mathrm{a}$ copper cathode and $8 \mathrm{kt} / \mathrm{a}$ cobalt in hydroxide production plant, followed by a flow sheet and supporting METSIM mass balance. As the drilling progressed, the plant design capacity was revised to $16 \mathrm{kt} / \mathrm{a}$ cobalt production. The life of the mine at this production rate is over 40 years.

In 2017, Chemaf approached Outotec and Metallurgical Engineering Technology and Construction(METC) for the detailed engineering and equipment supply for the Mutoshi project. The main objective was to design a project with minimal risk and maximized upside potential using the significant experience of both Outotec and METC engineers in metallurgical plant design and Chemaf's long experience in copper and cobalt plant operation and optimization. Metallurgical test work, process design, and the project delivery approach, as well as the decisions taken to achieve the above objectives, are discussed in this paper.

\section{Metallurgical test work}

A substantial amount of test work has been carried out using 2016 drill core samples from different areas within the Mutoshi complex and orebody with the purpose of (a) assessing the suitability of the ore to be processed through a hydrometallurgical route for both copper and cobalt recovery and (b) generating data to confirm specific plant operating parameters.

\section{Chemaf's research and development laboratory}

Chemaf has a well-equipped research and development complex with state-of-the-art facilities in Lubumbashi. The facility contains

* Consulting Metallurgist, Democratic Republic of Congo.

+ Chemicals of Africa SARL (CHEMAF), Democratic Republic of Congo.

* Outotec South Africa (Pty) Limited, South Africa.

$\S$ Outotec Finland (Pty) Limited, Finland.

\# METC, Africa.

(C) The Southern African Institute of Mining and Metallurgy, 2018. ISSN 2225-6253. This paper was first presented at the Copper Cobalt Africa, incorporating the 9th Southern African Base Metals Conference, 9-12 July 2018, Avani Victoria Falls Resort, Livingstone, Zambia. 


\section{The Mutoshi Project - Part I: Metallurgical test work, process design, and project delivery}

laboratory and pilot-scale crushers and ball mills, a work index ball mill, laboratory and pilot-scale ore beneficiation facilities (flotation and gravity separation), laboratory and pilot-scale batch and cascade leaching and precipitation facilities, laboratory and pilot-scale solvent extraction and electrowinning units, and a laboratory-scale ion exchange column. In addition, Chemaf has five large analytical laboratories located at three different sites: Usoke, Etoile, and Mutoshi, each equipped with ICP-OES (inductively coupled plasma optical emission spectrometry) and AAS (atomic absorption spectrophotometry). All of the above facilities were used for the metallurgical test work related to the Mutoshi project.

\section{Ore sampling}

The Mutoshi complex comprises several different ore sources and orebodies, namely the Kulumaziba tails (fine tails from the previous Anvil Mining heavy medium separation (HMS) operation), stockpiles (from the previous Gécamines mining operation), the Kumwehulu orebody, and the Mutoshi North and Mutoshi Central orebodies (AMC, 2016, 2017).

Metallurgical test work was conducted on each ore source as the drilling progressed. All drill cores used for the test work were selected and sampled under the supervision and guidance of AMC. The core samples used for SAG mill comminution (SMC) test work were selected using competency criteria. The samples were grouped into four lots: lot- 1 , lot-2, lot-3, and lot-4, representing respective composites of competent cores in the hangingwall of the orebody, the cobalt orebody (below the hangingwall), the copper orebody (below the cobalt orebody) in the footwall (below the copper orebody).

The samples used for other test work were selected based on their representativeness of the anticipated feed to the plant for the first five years of production. The stockpiles were initially sampled using a grid of $50 \mathrm{~m}$ spacing. The grid was laid out using a GPS and each sampling point was identified using three coordinates. Sample was collected on each identified point by digging to $20 \mathrm{~cm}$ depth.

Subsequently, a systematic drilling campaign was conducted on all the stockpiles under the supervision of AMC and following JORC procedure. All the stockpile ores were observed to be sticky in nature.

\section{Comminution test work}

The comminution test work was conducted in two campaigns: the Bond ball work index test work and the SMC and abrasion test work. The Bond ball work index tests were conducted internally at Usoke $\mathrm{R} \& \mathrm{D}$ Laboratory on core samples selected based on their representativeness of the orebody, and the SMC and abrasion test work were conducted at external accredited laboratories (GEMET, 2017; ROCKLAB, 2017) in South Africa on core samples selected based on their competency. The work index determination was conducted following the procedure proposed by Bond (1960), as described by Gupta and Yan (2006). The SMC tests were conducted following the standard method developed by Morrell (2004).

As primary ore comminution was to be performed using a high-steel milling process, most operating problems would relate to inadequate breakage of larger particles as the added steel balls would assist with primary ore breakage. As such, ore competency tests specifically focused on the more competent components of the ore and also whether any problems would be encountered due to foot- and hangingwall inclusion in plant feed material.

Figures 1 and 2 show the map of the Mutoshi permit and photographs of some core samples respectively. Figure 3 shows that there is quite a variation in the work index results

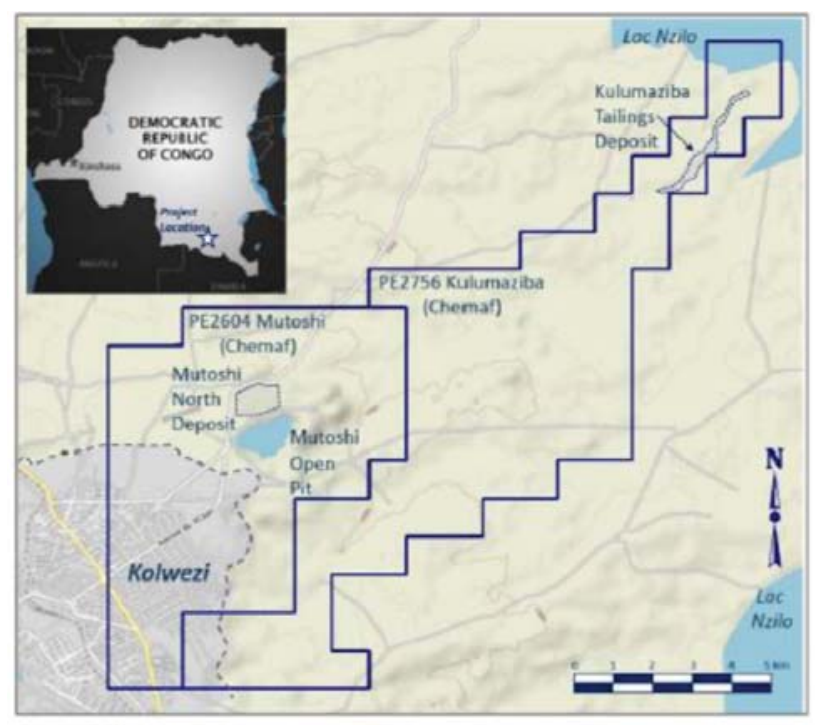

Figure 1-Mutoshi North permit location

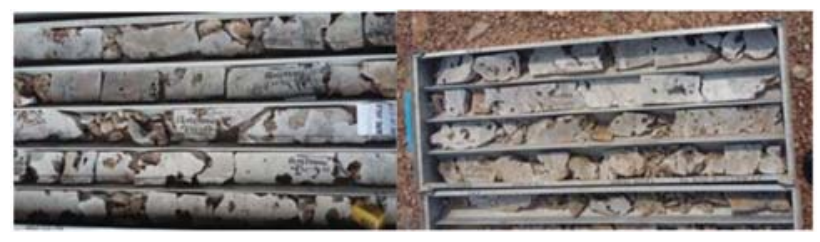

Figure 2-Mutoshi North cores selected for semi-autogenous comminution test work

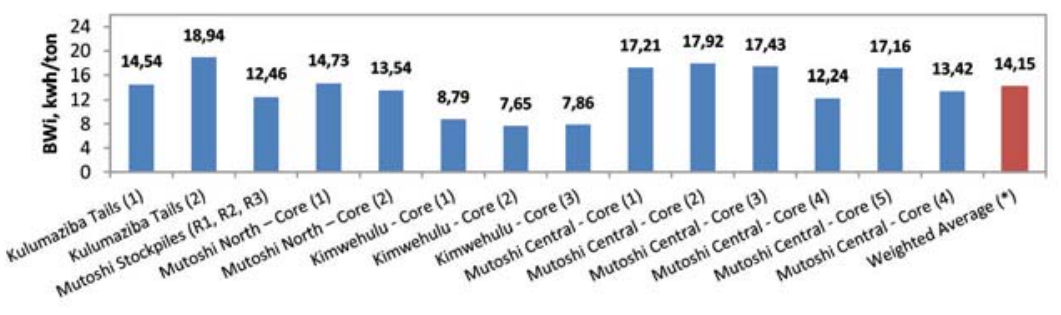

Figure 3-Bond ball work index results for Mutoshi ore 


\section{The Mutoshi Project - Part I: Metallurgical test work, process design, and project delivery}

from one orebody to another, which confirms the large variation in the characteristics of the Mutoshi ore. Even in the same orebody the work index varies up to $30 \%$ from one area to another. The results of SMC test work are presented in Table I. From the results, the estimates of parameters $A, b$, and $t_{a}$ required for the comminution circuit design and modelling were derived as shown in Table II.

The estimates of parameters derived from SMC testwork varied from $20 \%$ to $40 \%$ from one location to another within the same orebody. The variability in ore characteristics presented a challenge in the design of the comminution circuit. Although the samples were of more competent ores, it does confirm that the Mutoshi ores have harder and more power-intensive characteristics compared with other typical DRC copper orebodies, and this must be taken into account in the mill design. It highlights the need for good blending of the feed to the plant to maintain stable mill operation.

\section{Leaching and post-leach settling}

The leaching and post-leach settling test work aimed to assess the response of different Mutoshi orebodies to leaching and settling and generate data required for the

\begin{tabular}{|c|c|c|c|c|c|c|}
\hline \multicolumn{7}{|c|}{$\begin{array}{l}\text { Table I } \\
\text { Semi-autogenous mill comminution test work } \\
\text { results }\end{array}$} \\
\hline \multirow[t]{2}{*}{ Sample } & \multirow{2}{*}{$\begin{array}{c}\mathrm{DWi} \\
\left(\mathrm{kWh} / \mathrm{m}^{3}\right)\end{array}$} & \multirow{2}{*}{$\begin{array}{l}\text { DWi } \\
(\%)\end{array}$} & \multicolumn{3}{|c|}{ Mi parameters (kWh/t) } & \multirow{2}{*}{$\begin{array}{l}\text { Specific } \\
\text { gravity }\end{array}$} \\
\hline & & & Mia & Mih & Mic & \\
\hline & & 45 & & & & \\
\hline Lot 02 & & 31 & 18 & & 6.5 & \\
\hline Lot & & & & & & \\
\hline Lot 04 & 6.29 & 45 & 19.9 & 14.6 & 7.5 & 2.51 \\
\hline
\end{tabular}

DWi - drop weight index. Mia, Mih, Mic: comminution indexes respectively for tube mills, high-pressure grinding mills, and crushers

\section{Table II}

Parameters derived from semi-autogenous mill comminution test work results

\begin{tabular}{|l|c|c|c|}
\hline Sample & $\boldsymbol{A}$ & $\boldsymbol{B}$ & $\boldsymbol{t}_{\boldsymbol{a}}$ \\
\hline Lot 01 & 87.5 & 0.44 & 0.41 \\
Lot 02 & 71.8 & 0.64 & 0.50 \\
Lot 03 & 65.1 & 0.71 & 0.50 \\
Lot 04 & 64.8 & 0.61 & 0.41 \\
\hline
\end{tabular}

design and engineering of the leach and post-leach solidliquid separation circuits for the Mutoshi project.

The test work methodology adopted is outlined below:

> Leach and settling parameters were optimized on the Mutoshi North orebody samples

> Single tests were conducted on each of the rest of the Mutoshi ore sources (Mutoshi Central, Kulumaziba tails, Mutoshi stockpile, and Kimwehulu) under the above optimized conditions to assess their variability in behaviour compared with that of the Mutoshi North orebody.

The elemental compositions of the Mutoshi ores are presented in Table III.

The leaching optimization strategy focused on the following parameters: solids particle size distribution, $\mathrm{pH}$, ORP (oxidation-reduction potential), residence time, solids concentration in feed slurry, and temperature. Sulphuric acid was used as the lixiviant at controlled $\mathrm{pH}$ and sodium metabisulphite was used as reducing agent for the reduction of cobaltic ( $\left.\mathrm{CO}^{3}+\right)$ to cobaltous $\left(\mathrm{CO}^{2+}\right)$ at controlled ORP.

The results obtained from particle size distribution and residence time are presented in Figures 4 and 5, respectively.

Figure 4 shows that the leaching efficiency for both copper and cobalt increased as the size distribution became finer. This is due to the increase in leaching kinetics, which is linked with the liberation of valuable minerals; however, below a $P_{80}$ of $106 \mu \mathrm{m}$, the increase in both copper and cobalt leaching efficiency was very marginal while the dissolution of impurities increased significantly, with a consequent increase in reagent consumption. The optimum grind size for the Mutoshi North orebody is considered to be a $P_{80}$ of $106 \mu \mathrm{m}$.

Figure 5 shows that 4 hours of batch residence time is required to reach the maximum cobalt leaching efficiency whereas 2 hours is enough for maximum copper leaching. Four hours was therefore selected as the optimum residence time because it gives the maximum cobalt and copper

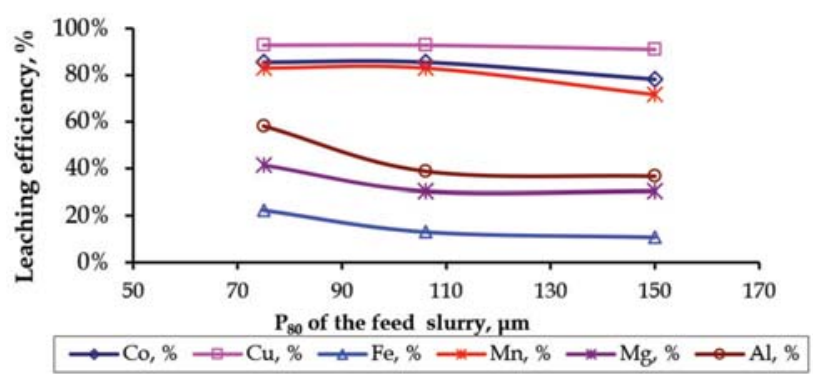

Figure 4-Effect of particle size on leaching efficiencies

Table III

Elemental composition of Mutoshi ores (all values in \%)

\begin{tabular}{|c|c|c|c|c|c|c|c|c|c|c|c|}
\hline Ore source & Total Cu & AS $\mathrm{Cu}^{*}$ & Total Co & AS Co & $\mathrm{Fe}$ & $M n$ & $\mathrm{Ca}$ & $\mathrm{Mg}$ & $\mathrm{Zn}$ & Al & $\mathrm{Ni}$ \\
\hline Mutoshi North & 1.80 & 1.73 & 0.50 & 0.45 & 1.99 & 0.16 & 0.69 & 1.40 & 0.01 & 0.88 & 0.01 \\
\hline Kulumaziba & 2.31 & 2.22 & 0.10 & 0.09 & 2.85 & 0.08 & 0.24 & 1.18 & 0.01 & 0.79 & 0.01 \\
\hline Kimwehulu & 1.16 & 1.10 & 0.02 & 0.02 & 2.99 & 0.05 & 0.21 & 1.34 & 0.01 & 1.87 & 0.01 \\
\hline Stockpiles & 1.16 & 1.11 & 0.08 & 0.07 & 2.48 & 0.16 & 1.02 & 2.44 & 0.04 & 1.28 & 0.01 \\
\hline
\end{tabular}




\section{The Mutoshi Project - Part I: Metallurgical test work, process design, and project delivery}

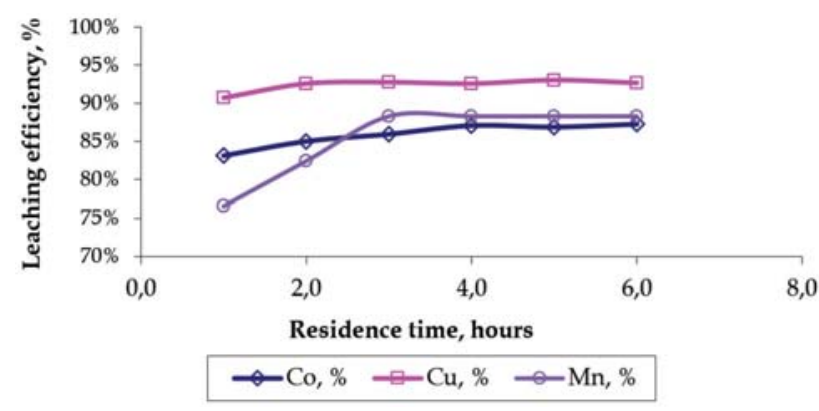

Figure 5-Effect of residence time on leaching efficiencies

recoveries. Based on past experience and other copper-cobalt plants in the region, Chemaf has always operated the leach plant at 30\% (by mass) solids concentration and below to minimize sands settling in the leach tanks. It was planned to design the Mutoshi leach section for similar conditions.

After a review of all leaching test work results for Mutoshi by Outotec, a recommendation was made to explore the possibility of operating the leach at higher solids concentration, with the objective of increasing metal tenors in solution and reducing the solution volumes to be handled downstream. Smaller solution volumes enable smaller equipment to be used in areas such as leaching, solvent extraction, ponds, and low-grade raffinate precipitation. The risks of sanding in reactors would be addressed by the Outotec OKTOP ${ }^{\circledR}$ agitation design. Therefore, the effect of solids concentration in the slurry was studied at optimized leach conditions.

From the results obtained and presented in Figure 6, it was observed that both copper and cobalt leaching efficiencies start dropping when the slurry solids concentration exceeds $35 \%$ by mass. This was chosen as the optimum solids concentration of the slurry. Thus, a reduction in leach solution volume of approximately $7 \%$ was achieved $(1-65 / 70=7.1 \%)$.

The temperature optimization investigation indicated that there was no further improvement in copper and cobalt leaching efficiency above $45^{\circ} \mathrm{C}$. No external heating will be required to attain this temperature. In fact, experience with several copper-cobalt plants in the DRC has shown that the heat generated by acid addition to closed leach reactors can maintain temperature within $45-50^{\circ} \mathrm{C}$. Figure 7 indicates the effect of temperature on leaching efficiencies.

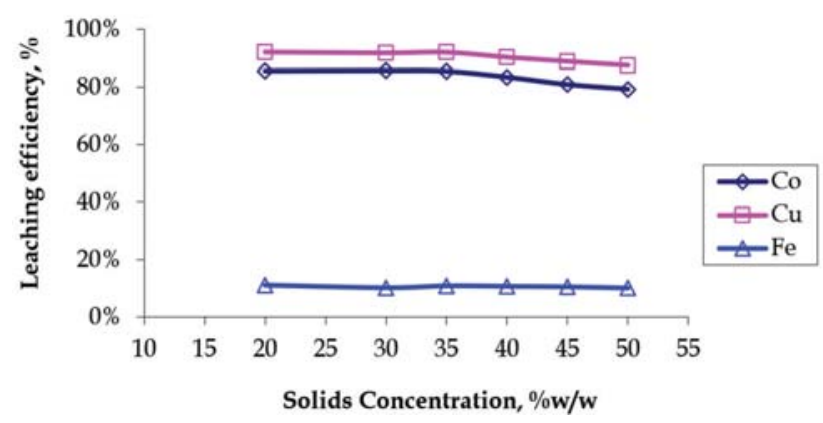

Figure 6-Effect of solids concentration on leaching efficiencies
Table IV shows the optimized leaching conditions and results obtained from test work and used for the Mutoshi leach circuit design.

The post-leach settling test work was conducted on leach slurry starting from flocculant screening, flocculant dosage, and slurry dilution optimization up to batch thickening to define the design settling flux. Different countercurrent washing scenarios were simulated using METSIM and HSC Chemistry software to arrive at the optimum operating conditions. The key objective for optimization was cobalt recovery, given the pricing environment. The optimized solid-liquid separation parameters are shown in Table V.

\section{Copper solvent extraction}

Based on results obtained from leaching and post-leach test work, METSIM and HSC simulations were developed to derive the pregnant leach solution (PLS) chemistries. From the PLS copper grades, the ideal extractant concentration in organic was calculated following the BASF procedure (Cognis Group, 2007). Then Isocalc simulations were developed and the results were reviewed and validated by BASF. Finally, laboratory tests, including McCabe-Thiele plots and

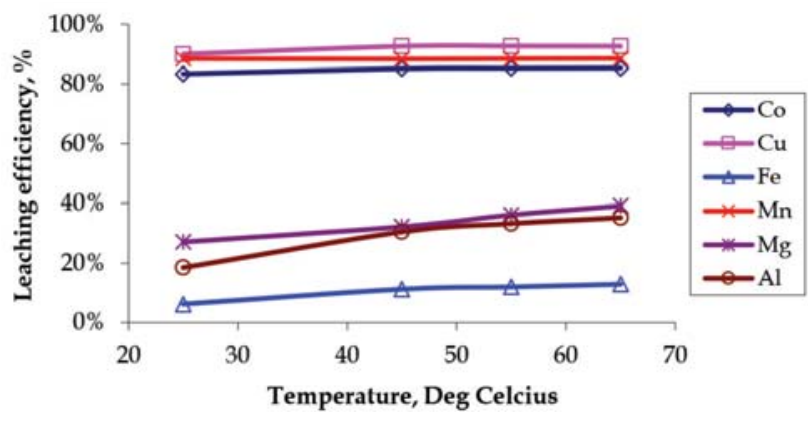

Figure 7-Effect of temperature on leaching efficiencies

Table IV

Optimized leach parameters and results

\begin{tabular}{|c|c|c|}
\hline Leach parameters & Unit & Value \\
\hline Leach feed particle size distribution $\left(P_{80}\right)$ & $\mu \mathrm{m}$ & 106 \\
\hline Residence time (batch) & $\mathrm{h}$ & 4 \\
\hline $\mathrm{pH}$ & - & 1.5 \\
\hline ORP (Eh) & $\mathrm{mV}$ & 350 \\
\hline Leach feed solids concentration & $\%(\mathrm{~m} / \mathrm{m})$ & 35 \\
\hline Temperature & ${ }^{\circ} \mathrm{C}$ & 45 \\
\hline Copper leach efficiency & $\%$ & 92 \\
\hline Cobalt leach efficiency & $\%$ & 85 \\
\hline Iron leach efficiency & $\%$ & 11 \\
\hline Manganese leach efficiency & $\%$ & 89 \\
\hline Silica in leach discharge liquor & $\mathrm{mg} / \mathrm{L}$ & $\sim 500$ \\
\hline Total acid consumption & $\mathrm{kg} / \mathrm{t}$ ore & 57 \\
\hline Gangue acid consumption (GAC)* & $\mathrm{kg} / \mathrm{t}$ ore & 37 \\
\hline Specific acid consumption ${ }^{\star \star}$ & $\mathrm{t} / \mathrm{t} \mathrm{Cu}+\mathrm{Co}$ & 3.8 \\
\hline Sodium metabisulphite consumption (as sulphur) & t/t Co & 0.7 \\
\hline
\end{tabular}

${ }^{*} \mathrm{GAC}$ (gangue acid consumption) is the acid consumed by all minerals in the ore excluding the valuable minerals (copper and cobalt minerals). It is generally calculated as the difference between the total acid consumed and the acid consumed by valuables minerals.

${ }^{* *}$ Specific acid consumption is simply the total acid consumption but expressed as tons of acid per ton of valuable metals contained in the ore 


\section{The Mutoshi Project - Part I: Metallurgical test work, process design, and project delivery}

\begin{tabular}{|l|c|c|}
\hline \multicolumn{2}{|l|}{$\begin{array}{l}\text { Table } V \\
\text { Optimized post-leach settling and countercurrent decantation parameters and results }\end{array}$} \\
\hline Post-leach parameters & Unit & Value \\
\hline Flocculant type & $\%(\mathrm{~m} / \mathrm{v})$ & Senfloc 5310 or equivalent (Rheomax DR 1050 suggested) \\
Flocculant strength & $\mathrm{g} / \mathrm{t}$ & 0.025 \\
Flocculant dosage & $\mathrm{t} / \mathrm{h} / \mathrm{m} 2$ & $60-80$ \\
Settling flux & $\%(\mathrm{~m} / \mathrm{m})$ & 0.351 \\
Underflow solids concentration & - & 55 \\
Countercurrent decantation (CCD) circuit configuration & - & Post-leach thickener + CCDs \\
Number of CCD units & $\%$ & 7 \\
Wash ratio (volume of solution to mass of solids) & $\%$ & 2.0 \\
Copper wash efficiency & $\%$ & 99.8 \\
Cobalt wash efficiency & & 99.7 \\
\hline
\end{tabular}

Table VI

Optimized copper solvent extraction parameters and results

\begin{tabular}{|l|c|c|}
\hline Copper solvent extraction parameters & Unit & Value \\
\hline Circuit configuration & - & Split circuit (series-parallel) - high grade (HG) - low grade (LG) \\
Copper in HG PLS & g/L & 4.0 \\
Copper in LG PLS & g/L & 1.7 \\
Acid in HG PLS & g/L & 3.1 \\
Acid in LG PLS & g/L & 2.0 \\
Advance O/A* ratio in HG extraction & - & 1.5 \\
Advance O/A ratio in LG extraction & - & 1.0 \\
Extractant & $\%(\mathrm{v} / \mathrm{v})$ & LIX \\
Extractant concentration & $\%$ & 17 \\
Overall copper extraction efficiency & $\mathrm{g} / \mathrm{L} / \%(\mathrm{v} / \mathrm{v})$ & 95.0 \\
Net copper transfer & $\%$ & 0.24 \\
Maximum loading of extractant & & 77
\end{tabular}

*Organic-to-aqueous flow rate ratio

countercurrent extraction and stripping simulations, were conducted to confirm the Isocalc parameters. Solvent extraction parameters derived from the above evaluation and used for design are given in Table VI.

\section{Cobalt recovery}

The cobalt recovery test work included impurity (iron and manganese) removal followed by cobalt precipitation and cobalt effluent treatment by magnesium precipitation. The test work was conducted on raffinate solution (copper-barren solution) generated from copper solvent extraction tests. Summarized optimized test work results are presented in Table VII.

\section{Process design}

The Mutoshi process was developed with the objective of minimizing risks and maximizing upside to the project. The major constraints considered in the overall design are discussed in the following sections.

\section{Easy project expansion}

Phase I of the Mutoshi project is designed for $20 \mathrm{kt} / \mathrm{a}$ and $16 \mathrm{kt} / \mathrm{a}$ copper and cobalt production, respectively. The plant is planned to be expanded in Phase II to achieve a final nameplate capacity of $100 \mathrm{kt} / \mathrm{a}$ copper. To this end, Phase I was designed for easy and cost-effective expansion.

> Overall plant throughput relates to an ore processing capability of $3.07 \mathrm{Mt} / \mathrm{a}$ at $0.85 \%$ acid-soluble $\mathrm{Cu}$ and $0.4 \%$ acid-soluble Co, increasing to $15.3 \mathrm{Mt} / \mathrm{a}$ with the throughput increase.

> The ore receiving and milling plant design was optimized such that future throughput would be achieved using two parallel two-stage grinding circuits, each having their own dedicated single-stage crushing facility. For initial plant operations, only one milling module with a single closed-circuit SAG mill is to be built with a design that allows easy expansion.

> The sticky ore precludes the use of conventional crushers and screens and intermediate storage, so a tooth-roll crusher with direct feed conveyance to the mill was chosen.

> Initial plant operations will mill a nominal $390 \mathrm{t} / \mathrm{h}$ through a single-stage SAG mill, with the future second mill (SAB) taking throughput up to $975 \mathrm{t} / \mathrm{h}$, which is half of the two-module $1950 \mathrm{t} / \mathrm{h}$ throughput capacity. Figure 8 illustrates the phased approach to comminution.

$>$ The specific expansion requirements of the mill required a mill discharge sump and cyclone cluster to be designed for the final two-mill circuit tonnage requirements. The mill feed conveyor, front-end bins, and crusher were also designed for future full-module tonnage throughput.

- The significant tonnage throughput change with the 


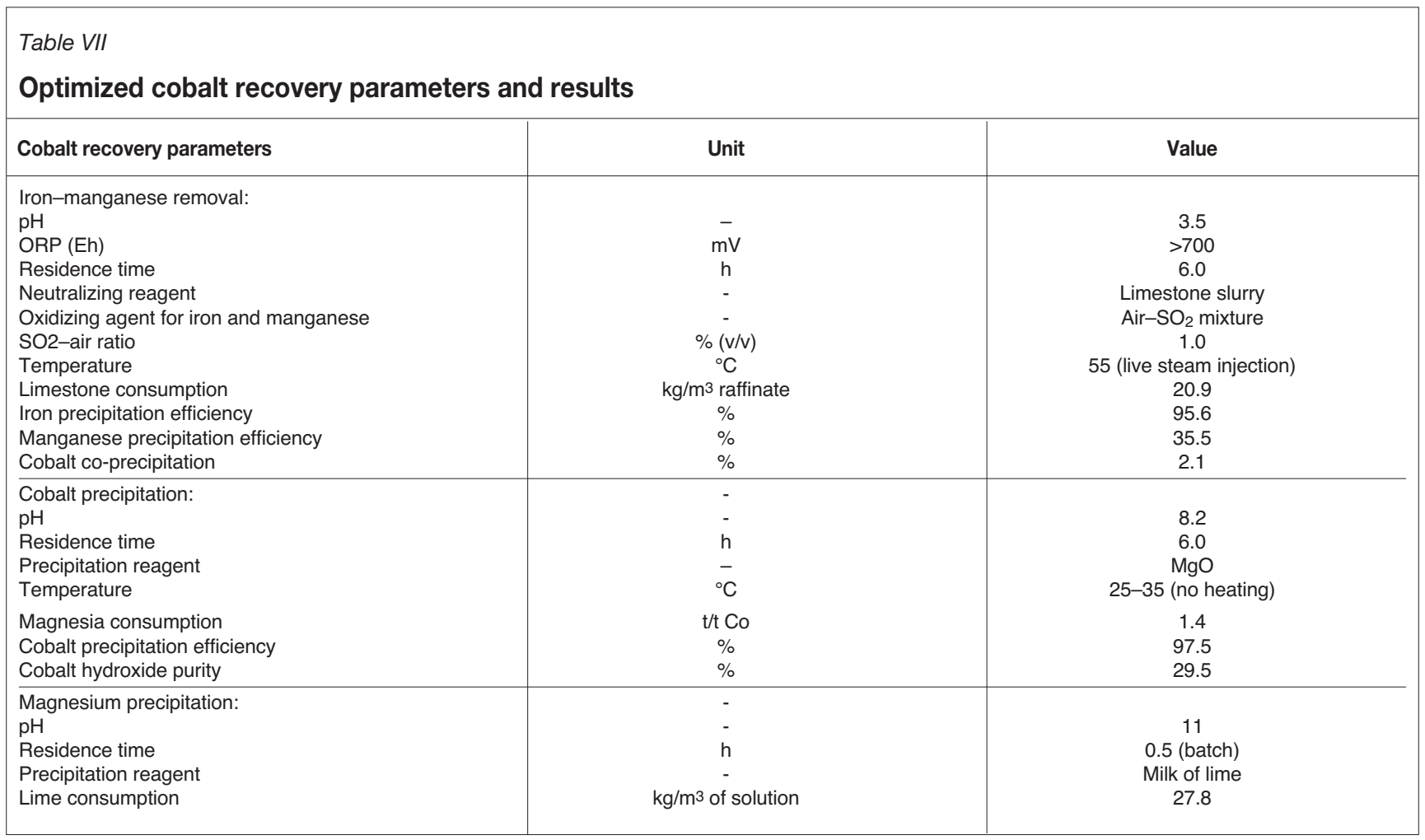

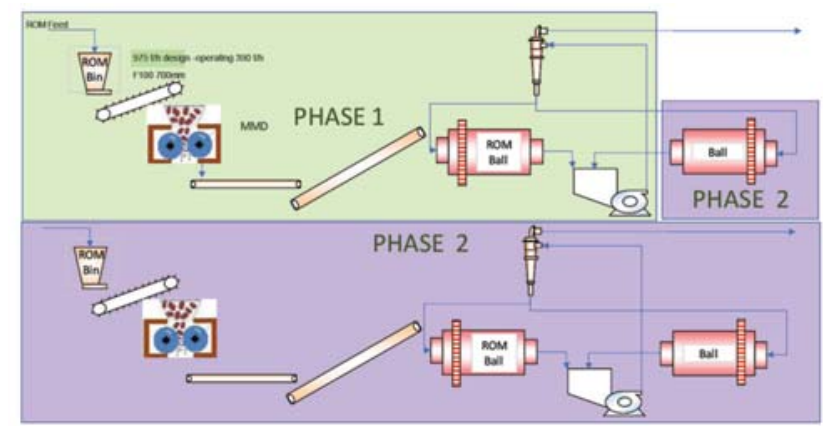

Figure 8-Mutoshi project comminution circuit

second mill installation will necessitate a change-out of cyclone feed pump and associated pipeline at this time.

> Both cyclone feed boxes and mill discharge tanks will be designed with additional nozzles to accommodate additional piping and pumping during the Phase II expansion and with minimum downtime.

\section{Variability in ore characteristics}

Metallurgical test work showed that the ore sources and orebodies exhibit more or less similar behaviour in leaching. There is, however, wide variability in the grindability and post-leach settling characteristics. This introduced a major challenge in the design of the comminution and post-leach solid-liquid separation circuits.

To minimize the risk of significant overdesign of the comminution and post-leach solid-liquid separation equipment, a strategy of defining an optimum blending of different ore sources, taking into account their total respective resources as well as the overall Mutoshi life-of- mine plan, was adopted. This optimum blending was used as basis for the design for the comminution and post-leach solid-liquid separation circuits.

In addition, due to the high proportion of fines in ore from the Mutoshi stockpiles and the sticky nature of these ores, a mineral sizer was selected as the best option for crushing and the crushed ore bin (surge between crusher and mill) initially planned in the design was eliminated. In its place, 6 hours' slurry surge storage capacity was provided between leaching and milling to enable the leach circuit to keep running in cases when the mill is down, and 36 hours of PLS storage capacity to keep the back end (copper solvent extraction and electrowinning and cobalt plant) running when the front end is down.

As silica is known to have adverse impacts on solvent extraction and electrowinning operations (Readett and Miller, 1995), PLS diluent wash stages are to be incorporated as part of the solvent extraction circuit, with the aim of removing silica and total suspended solids from both the LG and HG PLS before they enter the extraction stages.

\section{Metal recovery}

As the copper and cobalt grades in the feed are low, maximizing the metals recoveries, particularly cobalt, was another challenge. An opportunity for metals recovery improvement was identified at the countercurrent decantation (CCD) circuit. The process was initially designed with four CCD thickeners. Outotec later undertook an optimization study using simulations with $H S C$, and the results indicated that seven thickeners in the CCD circuit were required to achieve optimum recovery of both copper and cobalt when considering the cost and revenue benefits. Recovery of cobalt was more challenging than of copper because the specific wash waters used, although low in copper, still contain 


\section{The Mutoshi Project - Part I: Metallurgical test work, process design, and project delivery}

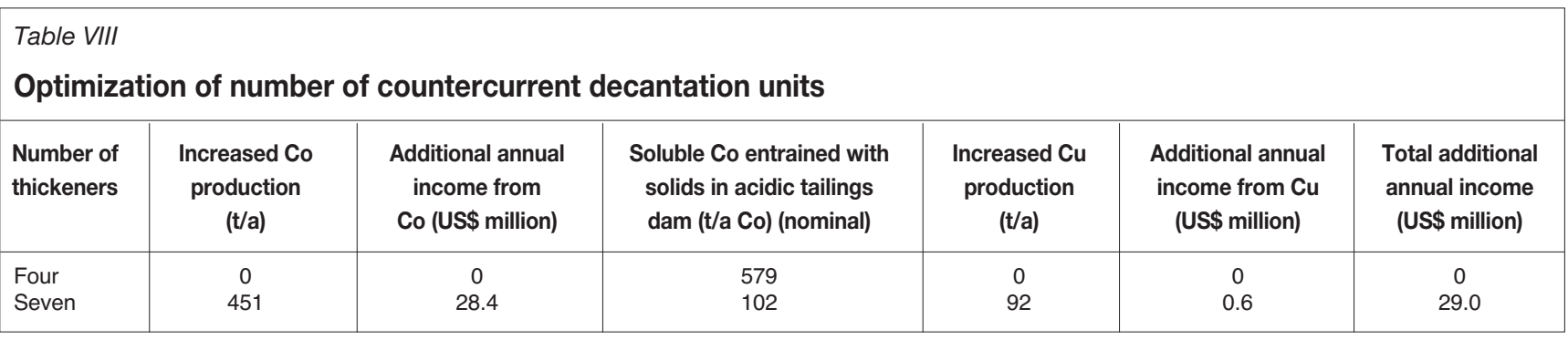

significant cobalt. An additional $451 \mathrm{t} / \mathrm{a}$ cobalt and $92 \mathrm{t} / \mathrm{a}$ copper are expected to be recovered by increasing the number of CCDs from four to seven, which would result in a total annual income of US\$29 million (calculations based on copper and cobalt sale prices of US\$7000 per ton and US\$63000 per ton, respectively). Table VIII summarizes the expected benefits of seven CCDs.

\section{Operating cost}

Optimizing plant design also entails tight control of operating cost, which will maximize profitability. For the Mutoshi process design, particular attention was placed on (a) minimizing acid consumption, which is the top operating cost-driver reagent and (b) achieving a negative water balance, which is a key to driving down metals losses due to neutralization of excess process solutions, driving down both acid and neutralizing reagent consumption.

As part of water balance optimization, and based on experience at other plants, including Etoile (Miller and Kendal, 2013), milling in raffinate was selected as the best method of minimizing the water introduced from post-milling solid-liquid separation. For similar reasons, the selection of the Kulumaziba tails re-mining (reclamation) method was a challenge. To this end, mechanical reclamation using an excavator followed by repulping in copper solvent extraction raffinate was considered the best option, instead of hydraulic mining using process water followed by solid-liquid separation. The milling and tailings reclamation with raffinate was integrated with a Split CircuitTM solvent extraction design, based on experience at other plants, including Etoile (Miller and Nisbett, 2007), for maximization of acid recycle from raffinate to the leach, subsequently minimizing the limestone requirement for acid neutralization from the raffinate bled to cobalt recovery.

The block flow diagram for the Mutoshi project is shown as Figure 9.

\section{Project delivery}

To achieve timeous delivery of the project and minimize design risks, the project delivery responsibilities have been divided between Outotec, METC, and Chemaf's process and construction team. Chemaf signed a fixed-price EPCS (Engineering, Procurement and Construction Supervision) contract with Outotec and METC, which was completely different from a traditional EPCM (Engineering, Procurement and Construction Management) contract. In this way, the project delivery time has significantly improved to date.

Chemaf's process team has taken responsibility for metallurgical test work, with the assistance of METC in cases of specific test work that was outsourced to external laboratories. In addition, developing and updating the process mass balance and process design criteria, as well as reviewing all the projects deliveries from Outotec and METC, was part of Chemaf's responsibilities.

The responsibilities of METC relate to all detailed engineering deliveries: process flow diagrams, piping and instrumentation diagrams, plant layout design, and civil, mechanical, and electrical designs. Outotec's scope is the delivery of a core engineering package that mainly focused on reviewing Chemaf's test work results and process design criteria to ensure they comply with the process requirements. Additionally, Outotec has a small detailed engineering supervision role, as well as a significant scope of delivery for the main process equipment and technology to the project. This includes, among other equipment, the LDX mill, OKTOP® reactors with agitators, thickeners, Vertical Smooth Flow (VSF®X) modular solvent extraction equipment, containerized crud treatment plant, filters, electrowinning, process control system (Proscon), and three modular sulphur-burning acid plants. The expected benefits of the modular pre-engineered plants that will be supplied by Outotec are lower total investment, shorter project lead time, lower project financing cost, less work at the construction site, less risk due to shorter project time at site, and residual value due to reusability of modules (Weatherseed et al., 2015).

\section{Conclusions}

By simplifying the project interfaces and scope for each party, and their respective expertise and experience, Chemaf, Outotec, and METC have developed a robust process design and project implementation plan for the Mutoshi project. The plant design has ensured low operating cost, optimized water balance, high metal recovery, and an optimized capital cost, while the innovative project implementation plan significantly accelerates the project execution timeframe in comparison with traditional models employed on the DRC Copperbelt. The project is currently under construction and expected to be commissioned in the third quarter of 2019.

\section{Acknowledgments}

The authors would like to thank Mr Shiraz Virji, Chairman of Chemicals of Africa, and the management team of the company for their permission to publish this paper.

\section{References}

African Mining And Consultants Ltd. 2016. Preliminary economic assessment of Mutoshi. 


\section{The Mutoshi Project - Part I: Metallurgical test work, process design, and project delivery}

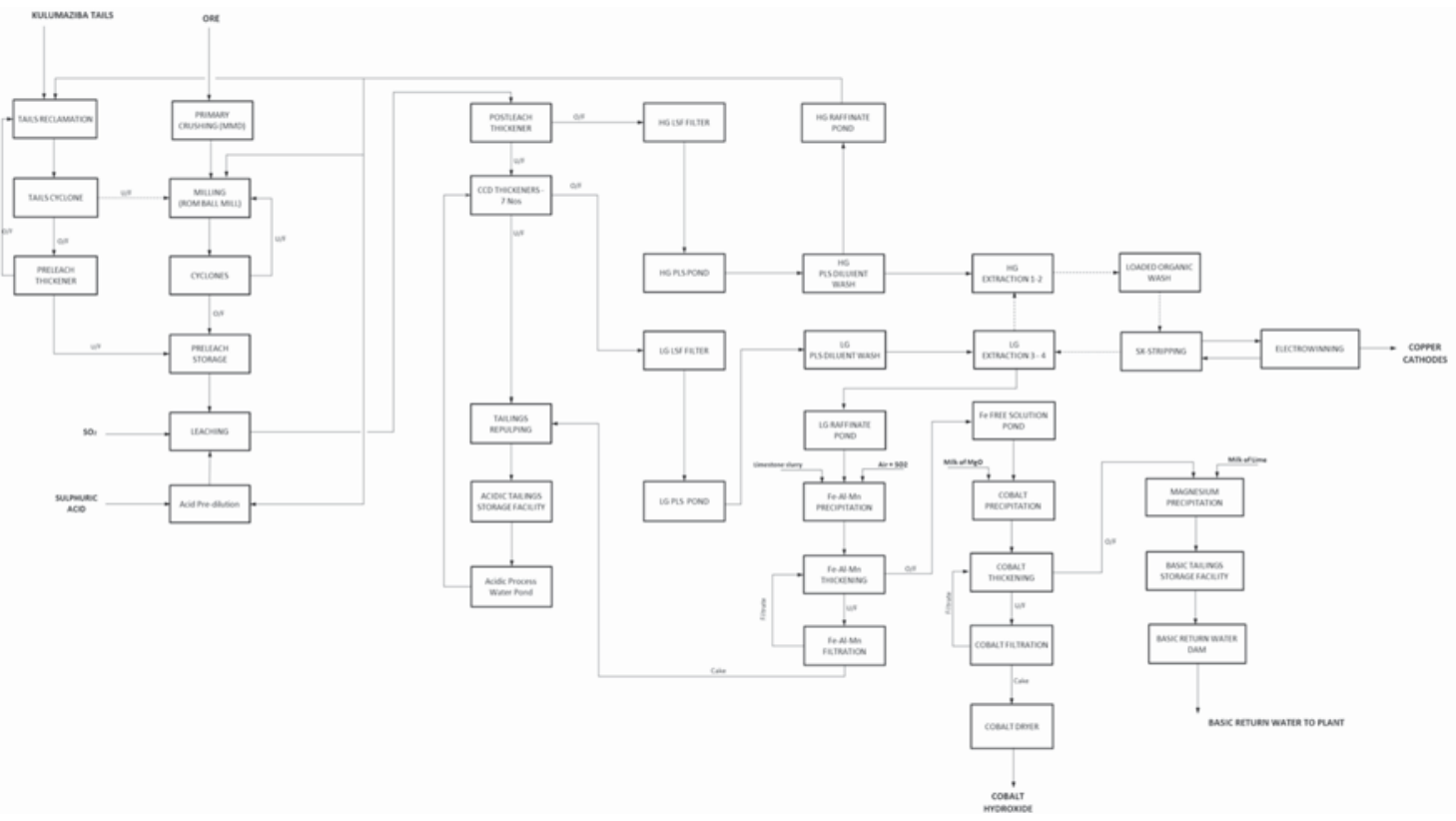

Figure 9-Mutoshi project process block flow diagram

African Mining and Consultants Ltd. 2017. Mutoshi life of mine feasibility study.

Chemaf Research and Development Laboratory. 2017. Mutoshi metallurgical testwork report.

Cognis CoRporation. 2007. LIX reagents redbook. Tucson, AZ.

GEMET. 2017. SMC test report for Mutoshi.

GuPTA, A. and YAn, D.S. 2006. Mineral Processing Design and Operation: An Introduction. Elsevier.

Miller, G. and NisBetT, A. 2007. Use of split circuit SX plants for high copper recovery and low operating costs. Proceedings of the ALTA Nickel/Copper/Cobalt Conference. ALTA Metallurgical Services, Melbourne.

MiLleR, G. and Kendal, K. 2013. Milling in acid-copper raffinate at the MUMI operation in DRC. Proceedings of the ALTA NickeVCopper/Cobalt Conference. ALTA Metallurgical Services, Melbourne, pp. 247-258.
MORELL, S. 2004. Predicting the specific energy of autogenous and semi autogenous mills from small diameter drill core samples. Minerals Engineering, vol. 17, no. 3. pp. 447-451.

READETT, D.J. and MILLER, G. 1995. The impact of silica in solvent extraction: Girilambone Copper Company, case study. Proceedings of Copper 95 Cobre 95, Vina del Mar, Santiago, Chile. Vol 3; Electrorefining and

Hydrometallurgy of Copper. Canadian Institute of Mining, Metallurgy and Petroleum, Montreal. pp. 679-690.

ROCKLAB. 2017. Rock properties tests for Mutoshi.

WeAtherseed, M., MatinheikKI, J., SAario, R., and FredriKsson, H. 2015. Modular mixer-settlers for SX plant sustainability. Proceedings of Copper Cobalt Africa, the 8th Southern African Base Metals Conference. Southern African Institute of Mining and Metallurgy, Johannesburg. pp. 335-345

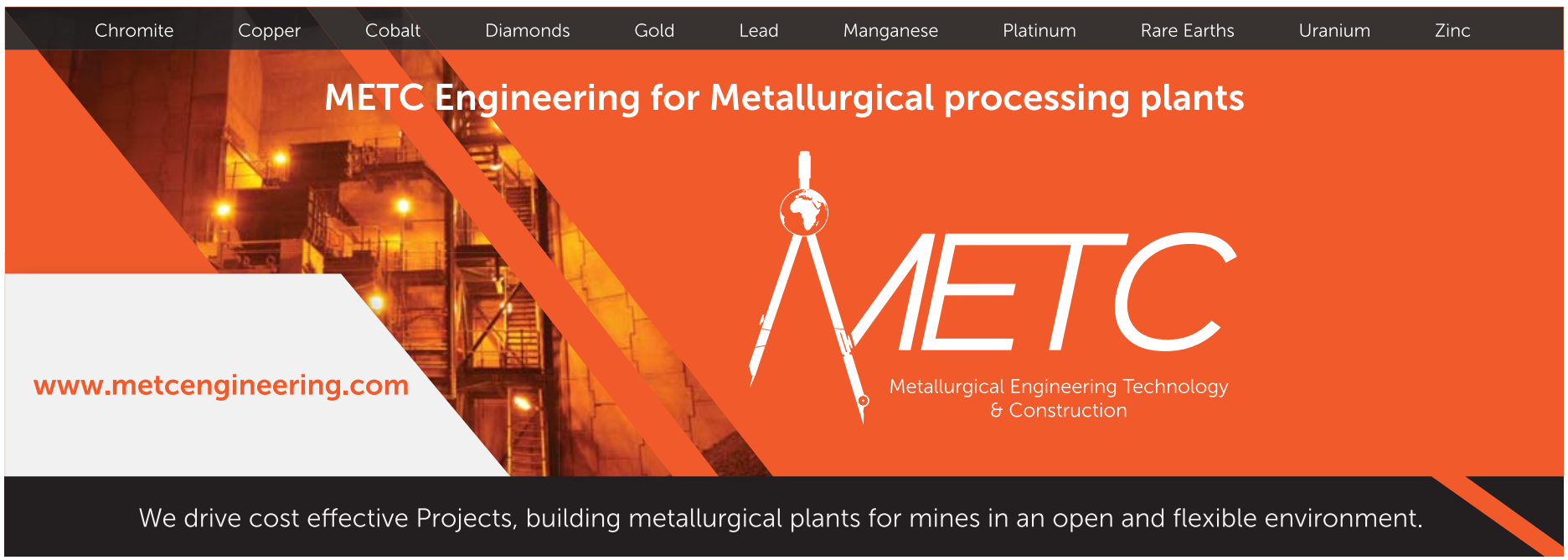

